\title{
Las televisoras vulneran la equidad en la contienda
}

\author{
Jesús Cantú Escalante
}

El trabajo hace una somera revisión teórica en torno a la importancia de la igualdad política en la democracia, así como del impacto de los sistemas mediáticos en dicha igualdad. Posteriormente, a partir del análisis de los resultados de 15 meses - de abril de 2011 a junio de 2012 - de monitoreo de los dos principales noticieros nocturnos de la televisión mexicana y tres diarios capitalinos se muestra, en el caso de la televisión, que los dos noticieros favorecieron la candidatura presidencial de la Coalición Compromiso por México, mientras los periódicos recrearon la pluralidad de la sociedad mexicana, mediante el llamado "pluralismo externo", que reproduce la diversidad a través del sistema mediático en su conjunto.

PALABRAS CLAVE: igualdad política, sistemas mediáticos, televisoras, elecciones, democracia

\section{Broadcasting Corporations Infringe Political Equality in Mexican Elections}

This paper reviews the importance of the political equality for democracy and the impact of media systems in this equality. It analyses the results of I5 months - from april of 20II untill june of 20I2- of monitoring the coverage of the presidential candidates in the two most important news programs in Mexican television, and three dailies of México City. It shows how the two broadcasting corporations favored the presidential candidate of the Coalition Compromise with Mexico, while the newspapers recreated the plurality of Mexican society, through the external pluralism, that reproduces the diversity across the media system.

KEYWORDS: political equality, media systems, broadcasting corporations, elections, democracy

Jesús Cantú Escalante: Escuela de Graduados en Administración Pública, Gobierno y Política Pública, Tecnológico de Monterrey, Monterrey, Nuevo León, México jce@itesm.mx 
$\mathrm{L}$ a igualdad política es una de las dimensiones indiscutidas y cruciales de la democracia. Los estudiosos de la ciencia política coinciden en que sin ésta, más allá de los impactos sobre las instituciones y requisitos, lo que está en riesgo es la democracia en sí misma. Y aunque señalan que hay que distinguir entre la igualdad política y la económica y social, también reconocen que las desigualdades en estos ámbitos "modelan profundamente directa e indirectamente" (Rueschemeyer, 2004: 76) a la primera. Larry Diamond y Leonardo Morlino afirman que "una buena democracia otorga a sus ciudadanos amplia libertad, igualdad política y control sobre las políticas públicas y los hacedores de éstas a través de instituciones estables, legítimas y legalmente funcionales" (Diamond y Morlino, 2004: 22). Es decir, la identifican como uno de los elementos indispensables de la misma. Lo que está en juego es el acceso a los recursos políticos, entendidos como "cualquier medio que una persona puede utilizar para influir sobre la conducta de otra persona" (Dahl, 2008: 64),

(1)

frecuentes; libertad de expresión, fuentes de información alternativas; autonomía de asociación, e inclusión de todos los miembros del demos- y seis requisitos de una democracia ideal — participación efectiva; igualdad en la votación; adquisición de conocimiento iluminativo; control final de la agenda; inclusión, y derechos fundamentales-. Según el autor, todas las instituciones están claramente vinculadas a los medios de información y cinco de los seis requisitos están relacionados, en mayor o menor medida, con el acceso a éstos. En función de lo anterior, el presente trabajo se enfoca a averiguar si los dos principales noticieros nocturnos de la televisión mexicana, así como tres diarios editados en la capital del país, garantizan dicha igualdad en su cobertura informativa.

La preponderancia de la televisión como medio de información política y la concentración de más de $97 \%$ de la audiencia en las dos principales cadenas televisivas - Televisa y TvAzteca - hacen casi obligatorio monitorear sus emisiones noticiosas. Los estelares son los noticieros nocturnos, que se transmiten por los canales principales de las televisoras, marcan la pauta al resto de los segmentos informativos y acaparan la mayor audiencia. Seleccionamos los noticieros nocturnos de ambas cadenas: de Televisa, "El Noticiero", conducido por Joaquín López Dóriga, transmitido por Canal 2; de TvAzteca, "Hechos", conducido por Javier Alatorre, transmitido por Canal 13. Aunque en México no existen periódicos nacionales, se optó por los tres periódicos de información general de mayor tiraje publicados en la capital de la república. Además de que presentan marcadas diferencias en su posición ideológica, ${ }^{1}$ los tres tienen impacto en otras ciudades del país a través de ediciones locales - Reforma en Monterrey y Guadalajara, La Jornada en nueve

\footnotetext{
${ }^{1}$ A partir del análisis de los artículos editoriales de los periódicos, el diario Reforma se ubica en una ideología de derecha - se estudiaron los artículos de Manuel J. Jáuregui, seudónimo de Rodolfo Junco-, La Jornada, de izquierda, y El Universal es cambiante dependiendo de si los temas son económicos, políticos o sociales (Pérez, 2010).
} 
ciudades del país, principalmente en el centro y el sur-, o bien a través de su agencia de noticias, como es el caso de El Universal, que tiene una importante presencia en diversos diarios del país. En primer lugar se hará una somera revisión teórica de los impactos de la igualdad política sobre las distintas dimensiones de la democracia. En el segundo apartado se hablará de las maneras de buscar la igualdad política en los sistemas mediáticos. En tercer término se delineará el sistema mediático mexicano. En cuarto lugar se revisarán los resultados del "Proyecto Observatorio de Medios y Opinión Pública" (EGAP, 2012). ${ }^{2}$ Finalmente se presentarán las conclusiones.

\section{LOS IMPACTOS DE LA IGUALDAD POLÍTICA}

En el presente apartado examinaré los impactos de la desigualdad política sobre el proceso de las políticas públicas, las contiendas electorales y, por ende, sobre la llamada "accountability" vertical, que aunque no son las únicas son las dimensiones que tienen que ver de forma directa o indirecta con la elección de los gobernantes. Dahl señala:

la experiencia del siglo xx demostró de manera concluyente que una economía de no mercado es [...] por el poder que necesariamente pone en manos de los gobiernos de controlar las decisiones económicas, incompatible con los controles democráticos sobre los líderes (Dahl, 2008: 75).

Sin embargo, entre las consecuencias adversas de la economía de mercado, afirma que "inevitablemente genera una enorme desigualdad de recursos entre los ciudadanos" (Dahl, 2008: 76). Esta disparidad en

\footnotetext{
${ }^{2}$ Contempla tres vertientes: observatorio de medios desde abril de 2011, la realización de 21 grupos de enfoque y cinco encuestas nacionales a teléfonos celulares para el estudio de la opinión pública. En este trabajo se utilizarán los resultados de la encuesta levantada del 25 al 28 de junio de 2012, es decir, en la víspera de la jornada electoral.
}

el acceso a los recursos políticos eventualmente pone en riesgo la vigencia de algunos de los derechos fundamentales, como el de la libertad de expresión, que puede estar garantizada constitucionalmente, pero no se materializa en una diversidad de opiniones y/o fuentes alternativas de información pública por la ausencia de espacios en los medios masivos de comunicación producto de la concentración en la propiedad o en su orientación a la trivialidad. Dietrich Rueschemeyer indica:

Los grupos dominantes pueden usar los recursos que les brinda su poder económico y social más o menos directamente en la esfera política. Y pueden utilizar su estatus e influencia sobre la educación, las producciones culturales y los medios masivos de comunicación - su hegemonía cultural, en síntesis - para modelar en una forma menos directa los puntos de vista, valores y preferencias de los grupos subordinados. Si estos efectos de la desigualdad social y económica no son sustancialmente contenidos, la igualdad política estará sumamente limitada (Rueschemeyer, 2004: 76).

Pero además de violentar otros derechos civiles, como advierten Diamond y Morlino, citando al mismo Rueschemeyer: los "individuos y grupos con mejor educación, más información y más recursos, inevitablemente tendrán más poder para modelar el debate público y las preferencias y determinar la elección de los líderes y las políticas" (Diamond y Morlino, 2004: 27). A decir de David Beetham una forma de subvertir los derechos civiles es a través de la formulación inadecuada de una legislación en la materia, y entre los ejemplos concretos a los que alude incluye la libertad de expresión: un "inadecuado pluralismo en materia de propiedad de los medios masivos de comunicación, opiniones e información pública, sea a través de oligopolios públicos o privados" (Beetham, 2004: 27). Para garantizar la igualdad en los procesos electorales hay que controlar dos aspectos centrales: el financiamiento para las campañas y el acceso a los medios masivos de comunicación. En cuanto al primero, la Constitución mexicana contempla un cuantioso financiamiento 
público, del que $30 \%$ se reparte en partes iguales entre todos los partidos políticos con representación en el Congreso de la Unión y 70\% en función del porcentaje de votación que obtuvieron en la última elección de diputados. De esta forma se garantiza que todos los contendientes tengan acceso a un mínimo de fondos para sufragar los gastos de una campaña electoral. En el ámbito de los medios masivos de comunicación, en particular radio y televisión, el artículo 41 constitucional establece las mismas reglas para la distribución de los llamados "tiempos comerciales", que en este caso son todos tiempos oficiales —de Estado y fiscales-, y la prohibición para partidos políticos y terceros de comprar espacios para promover o atacar a partidos o candidatos. Sin embargo, la regulación en torno a los contenidos emitidos fuera de los espacios comerciales es limitada y, sobre todo, carece de fuerza vinculatoria, pues la disposición contenida en el párrafo 7 del artículo
49 del Código Federal de Instituciones y Procedimientos Electorales (Cofipe) permite al Consejo General del Instituto Federal Electoral (IFE) formalizar - en acuerdo con las organizaciones de concesionarios y permisionarios - lineamientos generales aplicables a los noticieros, pero son simples recomendaciones.

Además, en el párrafo 8 del artículo 76 de la misma ley, se faculta al mismo Consejo General para que ordene "la realización de monitoreos de las transmisiones sobre precampañas y campañas electorales en los programas en radio y televisión que difundan noticias" (Cámara de Diputados, 2008: 31). La misma disposición le ordena difundir los resultados, por lo menos cada 15 días, a través de los tiempos oficiales a los que tiene derecho la autoridad electoral, pero éstos son indicativos y una eventual desigualdad no tiene consecuencia jurídica sobre ninguno de los actores políticos involucrados - medios,

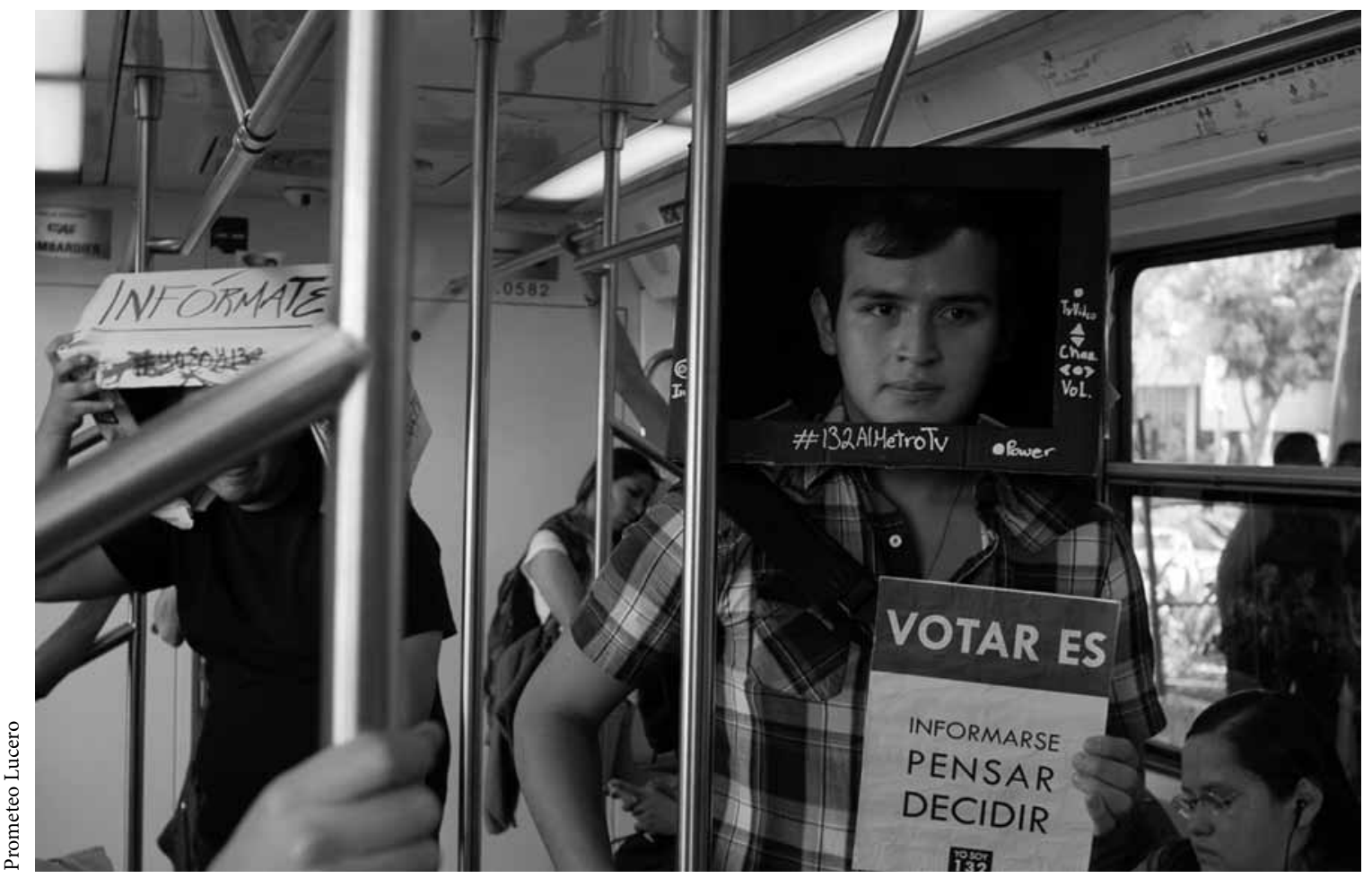

Performance de \#YoSoy132 en el metro de la ciudad de México, 13 de junio de 2012. 
partidos y candidatos-. Éste es el eslabón débil de la cadena que pretende garantizar la igualdad en la contienda electoral. Beetham (2004) apunta que para el cumplimiento de los derechos políticos, expresados fundamentalmente a través de la participación en los procesos electorales, uno de los problemas es el desnivel en el escenario electoral y es esencial que los medios masivos de comunicación realicen una cobertura no partidista de las campañas electorales, así como de las etapas previas. Es importante destacar que en una democracia representativa los procesos electorales cumplen, al menos, tres funciones: elegir representantes, identificar prioridades ciudadanas sobre las políticas públicas a partir de las propuestas programáticas de las distintas opciones políticas y llamar a cuentas a los gobernantes. Diamond y Morlino, al presentar el texto de G. Bingham Powell, Jr., puntualizan:

\begin{abstract}
los gobiernos democráticos son sensibles cuando el proceso democrático los induce a "diseñar e implementar las políticas públicas que los ciudadanos desean". Powell identifica tres enlaces en la cadena de receptividad democrática. Primero, las opciones se estructuran en una forma que destilan la diversidad ciudadana y las preferencias multidimensionales de políticas públicas en alternativas coherentes de políticas públicas a través de los programas de los partidos políticos. Segundo, las preferencias electorales de la ciudadanía se agregan (por medios distintos dependiendo del país) para conformar gobiernos de hacedores de políticas públicas. Y, tercero, los servidores públicos electos (y los designados por ellos) pueden convertir las ofertas políticas y los compromisos en propuestas concretas de políticas públicas (Diamond y Morlino, 2004: 27).
\end{abstract}

Esto implica que los dos primeros enlaces se concretan durante los procesos electorales a través de las ofertas programáticas de los partidos y candidatos y el voto ciudadano. Por tanto, si la competencia electoral no garantiza la igualdad en la difusión de las propuestas partidistas, el ciclo empieza mal y no inducirá a los gobernantes a responder a las necesidades ciudadanas. Así, la cadena inicia con la expresión de las demandas ciudadanas con la construcción de la agenda pública, continúa en el proceso electoral con la difusión de las propuestas partidistas y la elección ciudadana y termina con el diseño e implementación de las políticas públicas. Justo entre los elementos que Powell Jr. identifica como los que subvierten el proceso está lo que denomina el "control de la información”, claramente vinculado a la construcción de la agenda y la difusión de las propuestas de los partidos políticos. En concreto, lo define como "defectos en la disposición o habilidad de los ciudadanos para recolectar y procesar información precisa" (Powell, 2004: 97). Por otro lado, señala en específico a los medios masivos de comunicación que promueven un público informado como uno de los detonadores que favorecen una mayor respuesta democrática a las demandas ciudadanas. Acota que las "disposiciones legales que aseguren condiciones de igualdad o al menos mínimos garantizados de acceso a los medios masivos de comunicación a los principales candidatos y partidos puede ser de mucha ayuda" (Powell, 2004: 100). Prescribe:

La democracia de alta calidad es sostenible cuando los arreglos institucionales proveen los incentivos para soportar los vínculos de sensibilidad. Los incentivos deben fluir de: 1) el lanzamiento sistemático de los hacedores de políticas públicas ineptos o insensibles, incentivando a que sus sucesores anticipen e interpreten los deseos ciudadanos más cuidadosamente; 2) la elección directa de gobiernos fuertemente comprometidos con la realización de las políticas que la ciudadanía desea; y 3) la elección de múltiples partidos que están comprometidos a negociar, como agentes de los diversos subgrupos de ciudadanos que los eligieron, a favor de las políticas públicas que éstos impulsan (Powell, 2004: 92).

Y, nuevamente, los tres incentivos están muy vinculados a los procesos electorales, puesto que para Powell Jr. es central en el proceso de diseño de las políticas públicas y, por tanto, en el grado de sensibilidad de los gobernantes electos y su capacidad de respuesta a las preferencias ciudadanas, de suerte que si éste no ocurre en condiciones democráticas 
mínimas, toda la cadena se rompe. De este mismo párrafo de Powell Jr. puede derivarse el impacto de la desigualdad sobre la rendición de cuentas - accountability - vertical, pues el primer incentivo que destaca es la posibilidad de sancionar a los servidores públicos ineptos o insensibles, que es precisamente el último elemento de la rendición de cuentas.

Andreas Schedler (2004) especifica que son tres los pilares de la rendición de cuentas: información, justificación y responsabilidad o sanción. Si pensamos en la rendición de cuentas vertical, el primer pilar está totalmente en el ámbito del servidor público, el segundo supone de la interacción entre servidores y ciudadanía y el tercero recae en el terreno del ciudadano. Para los dos primeros se necesita la participación de los medios masivos de comunicación, ya que son los conductos para difundir la información proveniente del servidor público. En el segundo, deberían desempeñarse más como medios de comunicación plenos, pues por un lado tendrían que recoger los cuestionamientos, objeciones y duaclaraciones, precisiones y profundizaciones de los servidores públicos. Finalmente, con toda la información que recibió, el ciudadano debe emitir su veredicto en las urnas: castigar o premiar a los servidores públicos, según el caso. Así, el control ciudadano del poder, particularmente a través de la llamada "rendición de cuentas vertical", requiere de esta igualdad en el trato de los medios masivos de comunicación.

A partir de la argumentación de Dahl (2008) para vincular las seis instituciones básicas de la democracia con los requisitos o criterios mínimos que deben satisfacer para ser una democracia ideal, también es posible identificar la centralidad de los medios de comunicación en la igualdad política. Las seis instituciones de Dahl son: representantes elegidos -implica que las personas seleccionadas por el voto popular sean las máximas autoridades-; elecciones libres, justas y frecuentes - es decir, la existencia de un escenario electoral equilibrado para todos los competidores y con una determinada periodicidad-; libertad

de expresión - la garantía de que la ciudadanía puede expresar públicamente sus puntos de vista sin riesgo de ser castigada-; fuentes de información alternativas - posibilidad de acceder a fuentes ajenas al control de un determinado grupo político, económico o social—; autonomía de asociación — plena libertad para formar organizaciones independientes-, e inclusión de todos los miembros de la comunidad - que implica que todos tienen el mismo derecho a votar y ser votados, aun con limitaciones de edad y lugar-.

En su texto, Dahl vincula cada una de estas instituciones con lo que denomina "criterios" o "requisitos mínimos" que cada institución debe reunir e identifica, otra vez, seis de éstos: participación efectiva - la oportunidad de todos los miembros de una comunidad de expresar sus puntos de vista antes de que se adopte una política-, igualdad de votación - todos tienen derecho y oportunidad de votar y el valor del voto es igual para todos-, adquisición de conocimiento iluminativo - la igualdad de oportunidades para "aprender sobre políticas alternativas relevantes y sus consecuencias posibles" (Dahl, 2008: 23) —, control final de la agenda - lo cual implica que son los miembros de la comunidad quienes tienen "la oportunidad exclusiva de decidir" (Dahl, 2008: 24) qué asuntos forman parte de la agenda-, inclusión -cada miembro de la comunidad tiene el derecho de participar de acuerdo con todas las anteriores características - y derechos fundamentales - "cada una de las características necesarias de una democracia ideal prescribe un derecho" (Dahl, 2008: 24) —, por lo que la democracia consiste "necesariamente, [en] un sistema de derechos fundamentales" (Dahl, 2008: 24).

De lo anterior podemos colegir que cinco de los seis criterios mínimos requieren de medios masivos de comunicación plurales. El único que no los necesita en el acto mismo es la igualdad de votación, aunque sí en el proceso previo. En la tabla 1 se vinculan las instituciones con criterios. Dada la distribución de estos criterios todas las instituciones tienen una vinculación con los medios masivos de 
Tabla 1. Instituciones políticas y requisitos mínimos

\begin{tabular}{|c|c|}
\hline Instituciones políticas necesarias & Requisitos mínimos que deben satisfacer \\
\hline Representantes elegidos & $\begin{array}{l}\text { Participación efectiva } \\
\text { Control de la agenda }\end{array}$ \\
\hline Elecciones libres, justas y frecuentes & $\begin{array}{l}\text { Voto igualitario } \\
\text { Participación efectiva }\end{array}$ \\
\hline Libertad de expresión & $\begin{array}{l}\text { Participación efectiva } \\
\text { Conocimiento iluminativo } \\
\text { Control de la agenda }\end{array}$ \\
\hline Fuentes de información alternativas & $\begin{array}{l}\text { Participación efectiva } \\
\text { Conocimiento iluminativo } \\
\text { Control de la agenda }\end{array}$ \\
\hline Autonomía de asociación & $\begin{array}{l}\text { Participación efectiva } \\
\text { Conocimiento iluminativo } \\
\text { Control de la agenda }\end{array}$ \\
\hline Inclusión de todos los miembros del demos & $\begin{array}{l}\text { Participación efectiva del demos } \\
\text { Voto igualitario } \\
\text { Conocimiento iluminativo } \\
\text { Control de la agenda }\end{array}$ \\
\hline
\end{tabular}

Fuente: Dahl (2008: 27).

comunicación, lo cual hace indispensable asegurar la pluralidad del sistema mediático. Así, para lograr la igualdad política es imprescindible garantizar la igualdad de acceso a los medios, pero no únicamente en los espacios comerciales, sino también en el resto, es decir, noticieros, programas de análisis, programas de entretenimiento, telenovelas, etcétera.

\section{LA PLURALIDAD EN EL SISTEMA MEDIÁTICO}

Garantizar la igualdad en el acceso a los medios masivos de comunicación implica no únicamente permitir la presencia de los diferentes grupos de una sociedad, sino hacerlo de manera equilibrada para que todos los actores tengan las mismas posibilidades de expresar sus opiniones y presentar sus ofertas. Hay dos vías para alcanzar dicha pluralidad: pluralismo externo o interno. El primero: puede ser definido como el pluralismo alcanzado en el nivel del sistema mediático como un todo, a través de la existencia de una pluralidad de medios $u$ organizaciones que reflejan los puntos de vista de diferentes grupos o tendencias en la sociedad (Hallin y Mancini, 2004: 29).

En contraste, el interno es el que se alcanza "en cada medio u organización en lo individual" (Hallin y Mancini, 2004: 29). En términos generales, el pluralismo interno en los medios de comunicación está vinculado con el llamado "modelo liberal del sistema mediático" (Hallin y Mancini, 2004), que se caracteriza por un temprano desarrollo de la prensa comercial, producto de una economía de mercado muy desarrollada que permite a los medios el acceso a ingresos por publicidad altos, lo que lo orienta a buscar la neutralidad política y la profesionalización de los periodistas. Prácticamente no hay intervención del Estado y los medios de comunicación gubernamentales operan bajo el denominado "modelo 
profesional", es decir, bajo la batuta de consejos directivos integrados por profesionales de la comunicación y sin presencia de representantes del gobierno o de los partidos políticos. Los países que los autores ubican dentro de este modelo son Gran Bretaña, Estados Unidos, Canadá e Irlanda. De éstos, el único en el que hay pluralismo externo es Gran Bretaña, que es también, con Irlanda, donde la televisión gubernamental es fuerte.

En relación con el sistema político, estos países vivieron asimismo una temprana democratización y tienen un sistema bipartidista o el llamado "pluralismo moderado". El sistema electoral es de mayoría relativa y, por lo mismo, el sistema de gobierno es predominantemente mayoritario. Son países con fuerte orientación al liberalismo económico y tienen un importante desarrollo de los sistemas profesionales de carrera dentro de sus aparatos gubernamentales, lo que los lleva a tener una autoridad orientada al cumplimiento de la legalidad. En México no se cumplen ninguna de estas características, ni del

sistema mediático ni del político. En lo relativo al sistema mediático, fue hasta mediados de la década de los ochenta del siglo pasado cuando surgieron los primeros periódicos principalmente comerciales -El Financiero y después Reforma-, además de que la oligopolización de casi todas las ramas económicas - salvo algunas excepciones, como las agencias automotrices - tampoco obliga a una alta inversión publicitaria y menos a distribuirla con criterios puramente económicos.

En los otros parámetros tampoco se cumplen las premisas establecidas en los países del modelo liberal, pues los medios de comunicación gubernamentales son manejados claramente bajo el denominado "modelo gubernamental", es decir, sirven abiertamente al interés del partido gobernante, hay una débil profesionalización del ejercicio periodístico, debido, entre otras razones, por los bajos salarios del sector. Finalmente, hay una intervención gubernamental contundente en los medios por diversas vías. Las que más prevalecen en estos días son la compra de espacios comerciales con criterios estrictamente políticos y la entrega de importantes cantidades de recursos a periodistas y directivos. Lo mismo sucede con el modelo político. La democracia llegó a México al menos un siglo después de que lo hizo en los países del modelo liberal, y aquí apenas se puede hablar de ello en la última década del siglo xx. El sistema electoral es de mayoría relativa para la elección de los ejecutivos y proporcional para los legisladores, pero dalugara gobiernos fundamentalmente mayoritarios. En el ámbito económico, en particular a partir de la década de los ochenta del siglo pasado, busca insertarse en el liberalismo económico, pero por la fuerte oligopolización de la economía no puede hablarse estrictamente de economía de mercado, sino más bien de un híbrido en el que priman las prácticas oligopólicas o monopólicas bajo la tolerancia de las autoridades gubernamentales, muy de la mano con el alto nivel de clientelismo presente en la política mexicana y un muy débil servicio profesional de carrera y respeto de la legalidad (Cantú, 2012). La apuesta por el modelo liberal, más allá de la cercanía geográfica con el vecino país del norte, uno de sus más conspicuos representantes, tiene que ver con el hecho de que se le asocia con algunas de las características más valoradas en el periodismo, como una mayor y mejor profesionalización de los periodistas y la ausencia de instrumentalización política de los medios. ${ }^{3}$ Sin embargo, los mismos Hallin y Mancini reconocen los riesgos que afronta:

Ningún analista mediático serio argumentaría que el periodismo, en cualquier lugar del mundo, es literalmente neutral. Un tremendo volumen de investigación se ha dedicado a rebatir dicha noción, evidenciando que incluso donde los periodistas pueden estar sinceramente comprometidos con la ideología profesional de la "objetividad", las noticias incorporan valores políticos, que provienen de un

\footnotetext{
${ }^{3}$ Hallin y Mancini definen la instrumentalización como "el control de los medios por actores externos - partidos, políticos, grupos sociales o movimientos, actores económicos buscando influencias políticas- que los usan para intervenir en el mundo de la política" (Hallin y Mancini, 2004: 219).
} 
rango de influencias que van desde los patrones de reclutamiento de periodistas hasta las rutinas de la recolección de información y el compartir los presupuestos ideológicos de la sociedad en general. Tampoco sería correcto trazar una dicotomía muy definida entre la prensa comercial y la politizada: como veremos, la prensa comercial puede estar políticamente partidizada y la prensa no comercial -incluso aquella financiada por partidos políticos - puede adoptar normas de equilibrio político (Hallin y Mancini, 2004: 26-27).

Por otra parte, estos autores retoman en su estudio la tensión que genera en el modelo liberal que los medios de comunicación sean de propiedad privada y exista al mismo tiempo la expectativa de que cumplan con un servicio público o una responsabilidad social, que tanto se ha debatido en Estados Unidos. La otra contradicción que observan es la existente entre "la ética del periodismo profesional y las presiones del comercialismo" (Hallin y Mancini , 2004: 247), que además se agudizan en países con una alta concentración del ingreso caracterizados por la existencia de oligopolios en muchos ámbitos de la vida económica, pues el número de anunciantes importantes se reduce y el porcentaje de los ingresos del medio que depende de ellos se incrementa, lo que eleva su poder de presión. En el caso mexicano esto empeora por la inexistencia de una legislación que regule la compra de publicidad gubernamental y/o limite la arbitrariedad y discrecionalidad con la que los gobernantes distribuyen los recursos públicos, de manera que a nivel local los gobiernos estatales y municipales se convierten en los principales anunciantes de los medios y en el caso federal también son un cliente importante o preferente. Así que apostar al modelo liberal y, por ende, al pluralismo interno no es garantía de que se lograrán los efectos deseados. De hecho, los mismos autores destacan en referencia al caso griego:

En Grecia, Papathanassopoulos (2001) argumenta [que] las formas de periodismo crecientemente populares y orientadas al mercado no han eliminado el patrón de la instrumentalización política de los medios noticiosos, pero el balance de poder ha migrado de los políticos hacia los propietarios de los medios, que tienen crecientes y más poderosas herramientas de presión política. Desregulación y comercialización han producido sensacionalismo, pero no neutralidad, de acuerdo con Papathanassopoulos, quien citando a Zaharopoulos y Parsachos (1993: 96) comenta que "la inmensa mayoría de medios griegos son 'imperturbablemente' partidistas, sensacionalistas y políticos" (Hallin y Mancini, 2004: 285).

A pesar de todo ello, en México se apuesta por el pluralismo interno que, como se demostrará en las páginas siguientes, no se concreta ni en la televisión ni en la prensa escrita, si bien en ésta - al menos en la capital de la república - se logra un pluralismo externo que permite la vigencia de una mayor igualdad política en el acceso a los medios. Lamentablemente esto no sucede en el resto del país, aunque este aspecto no es motivo de este estudio.

\section{EL SISTEMA MEDIÁTICO MEXICANO}

La actividad televisiva mexicana se concentra alrededor de las dos empresas que poseen cadenas con cobertura nacional: Televisa y TvAzteca. De acuerdo con una gráfica de Huerta-Wong y Gómez (2013), mantienen prácticamente inalterada la participación de la audiencia desde 1997 hasta la fecha: entre 68 y $70 \%$ para Televisa, 27 y el 30\% para TvAzteca y de 2 a $3 \%$ para el resto de los participantes. Es decir, estas dos televisoras acaparan entre 97 y el 98\% de la audiencia televisiva nacional. El problema se agudiza en los mercados locales, como puede deducirse de un artículo de Raúl Trejo Delarbre (2011), en el que indica que en 18 de las 32 entidades federativas la única opción de televisión comercial para los televidentes son los canales de alguna de las dos empresas, en nueve estados hay además una opción local o regional, en cuatro tienen dos alternativas más y sólo en Baja California cuentan con cuatro canales locales. Los gobiernos de 27 entidades operan sus propias televisoras. La señal de Canal 11, del Instituto Politécnico Nacional, llega a 19 entidades a partir del 
impulso de que fue objeto durante el sexenio pasado. En cinco estados las universidades públicas operan sus canales. En todos los casos la participación en la audiencia televisiva es muy limitada.

Huerta-Wong y Gómez aplican tres índices de concentración a la televisión mexicana. En los tres casos los resultados muestran lo extremadamente concentrado del mercado televisivo mexicano. Para el Índice Hirschman-Herfindhal (HHI), que suma los cuadrados de la participación de la audiencia de cada uno de los participantes en un mercado, cuando el resultado es igual o mayor a 4 se considera que el mercado es extremadamente concentrado. El índice de concentración de las cuatro firmas más grandes (CR4) es la suma del porcentaje de participación de mercado de estas compañías, y si el resultado es igual o superior a $50 \%$ se considera altamente concentrado. El Índice Noam, desarrollado por Eli
Noam, toma el resultado del HHI y lo divide entre la raíz cuadrada del número de participantes, pues pretende atemperar esta cifra con la diversidad existente, de tal forma que cuando dicha operación arroja un resultado igual o mayor a 1.8 también se considera extremadamente concentrado. Los investigadores aplicaron los tres índices al mercado televisivo mexicano desde tres aproximaciones: tomaron datos de los porcentajes de audiencia, de los porcentajes de concesiones de televisoras y de la participación del mercado publicitario. En los nueve casos - la aplicación de los tres índices con las tres aproximacionesel resultado es un mercado televisivo altamente concentrado. Los autores realizaron el mismo ejercicio para otros medios masivos de comunicación y el resultado es interesante, en particular en lo que respecta a la radio. Se aplicaron los índices a cada uno de los 15 principales grupos radiofónicos y un

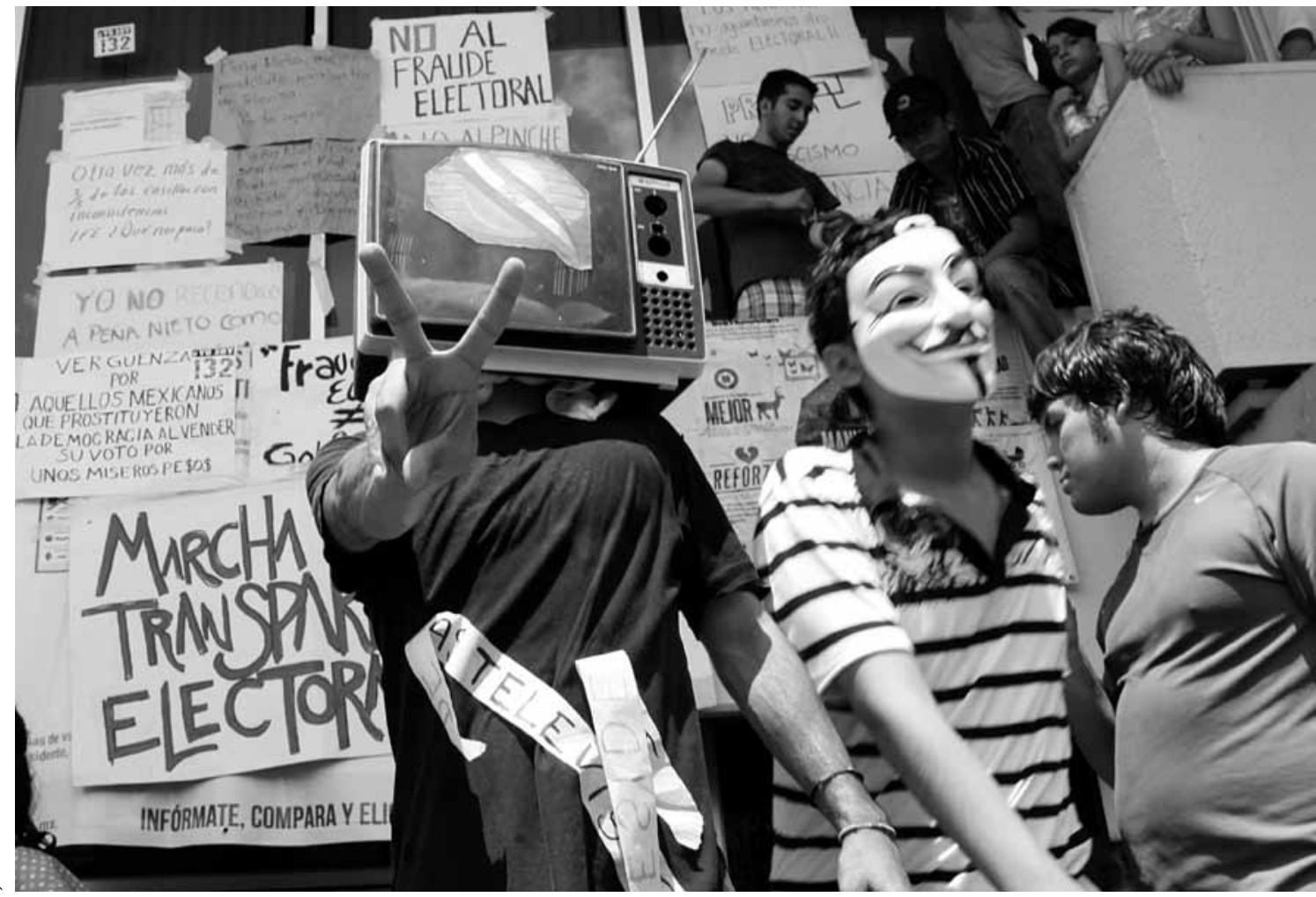

Protesta de \#YoSoy132, Sinaloa, 2012. 
agrupado de 37 concesionarios en "otros" a partir del número de estaciones de radio concesionadas. Los índices HнI y Noam reportan que no hay concentración, y el cr4 indica una concentración moderada.

La excesiva concentración es, al mismo tiempo, causa y efecto de una legislación en materia de medios de comunicación muy deficiente. Es un efecto porque la normatividad incorrecta en materia de telecomunicaciones, en especial de radio y televisión, que data de 1960, no tan sólo la permite sino que provoca la concentración, y causa porque el poder que acumulan las dos televisoras impide aprobar las reformas que se requieren. La obsolescencia y las deficiencias de la legislación en la materia abarcan prácticamente todos los ámbitos vinculados con los medios de comunicación, desde la Ley Federal de Radio y Televisión y la Ley de Imprenta — sin reformas sustantivas desde 1917-, hasta la ausencia de una ley reglamentaria para el derecho de réplica consagrado en la Constitución o la aplicación del artículo 134 constitucional, que pretende evitar el uso de los recursos públicos destinados a la publicidad gubernamental en beneficio de los gobernantes. Y, salvo en el caso del Distrito Federal, tampoco hay una legislación adecuada en materia de delitos contra el honor.

\section{EL COMPORTAMIENTO DE LOS MEDIOS MASIVOS DE COMUNICACIÓN ${ }^{4}$}

Desde febrero de 2011 inició la sistematización de la información que difundían los dos principales noticieros nocturnos de la televisión mexicana, así como de las primeras planas de tres diarios publicados

\footnotetext{
${ }^{4}$ Los datos en este apartado provienen del "Proyecto Observatorio de Medios y Opinión Pública" (EGAP, 2012). Quiero agradecer en particular el trabajo y apoyo de las maestras en análisis político y medios de información Rocío Galarza y Alma Rosa Suárez, y al doctorando Everardo Díaz, que hicieron posible la recolección y sistematización de la información con el apoyo de becarios de la citada maestría.
}

en la capital del país. Esto permitió identificar a los actores que aparecen en los medios, ubicar dicha aparición y el tema de las notas informativas. A partir del inicio de las campañas, el 30 de marzo de 2012, se incluyeron variables a dicha sistematización en lo referente a la presencia de candidatos a la presidencia de la república y sus campañas electorales, para determinar, entre otras, el tono de la cobertura - positiva, negativa o neutra- y la revisión de los periódicos se amplió a los ejemplares completos. ${ }^{5}$

El periodo que se analiza cubre del 1 de abril de 2011 al 30 de junio de 2012, es decir, un año antes del inicio de las campañas y hasta la víspera de la jornada electoral. Para el análisis la cobertura se dividirá en tres momentos: 1) el previo al inicio de los procesos de selección interna de los candidatos de las fuerzas políticas, que comenzaron el $19 \mathrm{de} \mathrm{di-}$ ciembre de 2011, por lo que se revisará la información divulgada del 1 de abril al 30 de noviembre de 2011;2) de diciembre de 2011 a marzo de 2012, y 3) el periodo de campañas electorales: de abril a junio de 2012. En los dos primeros periodos se analizan sólo los espacios en los que el candidato o gobernante es el actor principal -aparece con voz, imagen o ambos- o cuando el único aludido, el beneficiario o el perjudicado por la información emite el comentario. En cambio, en el último periodo se incluyen todos los espacios que mencionen a los candidatos o sus campañas, por eso el notable incremento de notas.

\section{Análisis del periodo previo al inicio de precampañas}

Al revisar el número de notas y la cantidad de tiempo que los noticieros de televisión dedicaron a quienes posteriormente resultaron los candidatos de las tres

\footnotetext{
${ }^{5}$ Explico sólo las adiciones que utilizaremos en el presente trabajo, pues la observación contempló la inclusión de variables relacionadas con la teoría del framing, pero no abundo en ellas por motivos de espacio y por el objetivo del artículo.
} 
Tabla 2. Número de notas por candidato y noticiero

\begin{tabular}{|c|c|c|c|c|c|c|}
\hline \multirow{2}{*}{ Candidato } & \multicolumn{2}{|c|}{ "El Noticiero" } & \multicolumn{2}{|c|}{ "Hechos" } & \multirow{2}{*}{ Total notas } & \multirow{2}{*}{ Total \% } \\
\hline & Notas & $\%$ & Notas & $\%$ & & \\
\hline EPN & 33 & 66.0 & 30 & 75.0 & 63 & 70.0 \\
\hline AMLO & 12 & 24.0 & 6 & 15.0 & 18 & 20.0 \\
\hline JVM & 5 & 10.0 & 4 & 10.0 & 9 & 10.0 \\
\hline Total & 50 & 100.0 & 40 & 100.0 & 90 & 100.0 \\
\hline
\end{tabular}

Fuente: Elaboración propia con datos de EGAP (2012).

Tabla 3. Cantidad de segundos mensuales por candidato

\begin{tabular}{lrrrr}
\hline \multicolumn{1}{c}{ Mes } & EPN & AMLO & $J V M$ & Total \\
\hline Abril 2011 & 342 & 80 & 0 & 422 \\
\hline Mayo & 1054 & 0 & 0 & 1054 \\
\hline Junio & 1113 & 43 & 0 & 1156 \\
\hline Julio & 701 & 47 & 91 & 539 \\
\hline Agosto & 385 & 0 & 122 & 2076 \\
\hline Septiembre & 1631 & 114 & 631 & 1559 \\
\hline Octubre & 455 & 444 & 28 & 3217 \\
\hline Noviembre & 1381 & 1808 & 1232 & 10830 \\
\hline Total & 7062 & 2536 & 11.4 & 100.0 \\
\hline \% del tiempo total & 65.2 & 23.4 & & 2076 \\
\hline
\end{tabular}

Fuente: Elaboración propia con datos de EGAP (2012).

principales fuerzas políticas nacionales se percibe con toda claridad la disparidad en la cobertura. La diferencia es de 3.5 notas contra una entre Enrique Peña Nieto, quien después fue el candidato de la Coalición Compromiso por México, y Andrés Manuel López Obrador, candidato del Movimiento Progresista, y de siete a una entre el primero y la candidata del PAN, Josefina Vázquez Mota, tal como se corrobora en la tabla 2. La distancia se reduce ligeramente al hacer la comparación en la cantidad de segundos, de casi tres a uno, en el primer caso, y de casi seis a uno, en el segundo, como se muestra en la tabla 3.

Una explicación para el tratamiento privilegiado para quien fuera gobernador del Estado de México hasta el 15 de septiembre de 2011 es precisamente que esta posición lo involucraba en eventos que eran de suyo noticiosos, y por tanto las televisoras le daban cobertura. Sin embargo, al contrastarla con la de otros actores políticos que detentaban puestos políticos de similar o mayor jerarquía, como Marcelo Ebrard Casaubón (MEC), jefe de Gobierno del Distrito Federal, y el entonces presidente Felipe Calderón Hinojosa (FCH), también es evidente la ventaja del gobernador tricolor. En el periodo analizado la presencia de Peña Nieto es muy superior a la de Ebrard, cuyas responsabilidades eran similares -si no es que mayores, por ser el gobernante de la capital de la república-. La relación del espacio brindado a uno y a otro es de 3 a 1 y la presencia en pantalla de Ebrard resulta comparable únicamente en agosto y superior en octubre, cuando rindió su informe de labores. 
Tabla 4. Cantidad de segundos mensuales por gobernante

\begin{tabular}{lrrl}
\hline \multicolumn{1}{c}{ Mes } & EPN & MEC & FCH \\
\hline Abril 2011 & 342 & 0 & 1622 \\
\hline Mayo & 1054 & 240 & 4470 \\
\hline Junio & 1113 & 245 & 2432 \\
\hline Julio & 701 & 190 & 1427 \\
\hline Agosto & 385 & 306 & 3711 \\
\hline Septiembre & 1631 & 399 & 1904 \\
\hline Octubre & 455 & 803 & 1996 \\
\hline Noviembre & 1381 & 150 & 2307 \\
\hline Total & 7062 & 2333 & 19869 \\
\hline
\end{tabular}

Fuente: Elaboración propia con datos de EGAP (2012).

Tabla 5. Número de notas por candidato y periódico

\begin{tabular}{|c|c|c|c|c|c|c|c|}
\hline \multirow{2}{*}{ Periódico } & \multicolumn{2}{|c|}{$E P N$} & \multicolumn{2}{|c|}{$A M L O$} & \multicolumn{2}{|c|}{$J V M$} & \multirow{2}{*}{ Total } \\
\hline & Notas & $\%$ & Notas & $\%$ & Notas & $\%$ & \\
\hline El Universal & 18 & 66.7 & 5 & 18.5 & 4 & 14.8 & 27 \\
\hline La Jornada & 15 & 40.5 & 18 & 48.7 & 4 & 10.8 & 37 \\
\hline Reforma & 14 & 60.9 & 7 & 30.4 & 2 & 8.7 & 23 \\
\hline Total & 47 & 54.0 & 30 & 34.5 & 10 & 11.5 & 87 \\
\hline
\end{tabular}

Fuente: Elaboración propia con datos de EGAP (2012).

En la comparación con el presidente de la república llama la atención septiembre, mes en que Calderón rindió su Quinto Informe de Gobierno y Peña Nieto entregó la gubernatura. Para la televisión mexicana los dos eventos merecieron la misma atención. Al comparar con la cobertura de los medios impresos, que registran mayor equilibrio, se observa aun más claramente el tratamiento privilegiado de las televisoras para EPN. En la tabla 5 puede percibirse que, aunque Peña Nieto tiene mayor presencia en función de su cargo gubernamental, AMLO y JVM presentan el doble de cobertura de la que tienen en la televisión, y que López Obrador logra más de la tercera parte de las notas informativas, en particular por las primeras planas de La Jornada. Y si se compara con los gobernantes de ese momento, como en la tabla 6 , también se observa un comportamiento lógico. Es decir, se constata que la presencia de Ebrard y Peña Nieto en el total de notas publicadas es muy similar. La diferencia de cuatro notas más para el perredista puede explicarse porque encabeza el gobierno de la capital. En el caso del presidente su mayor presencia se explica en función de su responsabilidad. Además, es evidente la diferencia en las coberturas de los tres periódicos, que se analizarán más adelante con mayor detalle.

En cuanto a los noticieros televisivos, también hicieron su aparición los "infomerciales", espacios informativos en los que se transmiten materiales con una evidente intención de promover al actor político, sin revelar a la audiencia el contenido publicitario del mensaje. En un dictamen que Julio Juárez realizó para el IFE, señaló que la intención de estos segmentos es lograr un mayor impacto en el televidente: 
Tabla 6. Número de notas por gobernante y periódico

\begin{tabular}{lcccccccc}
\hline \multirow{2}{*}{ Periódico } & \multicolumn{3}{c}{ EPN } & \multicolumn{3}{c}{ MEC } & FCH & Total \\
\cline { 2 - 7 } & Notas & $\%$ & Notas & $\%$ & Notas & $\%$ & 53 \\
\hline El Universal & 18 & 20.9 & 25 & 29.1 & 43 & 50.0 & 74.2 & 97 \\
\hline La Jornada & 15 & 15.5 & 10 & 10.3 & 72 & 43.4 & 86 \\
\hline Reforma & 14 & 26.4 & 16 & 30.2 & 23 & 58.5 & 236 \\
\hline Total & 47 & 19.9 & 51 & 21.6 & 138 & & 53 \\
\hline
\end{tabular}

Fuente: Elaboración propia con datos de EGAP (2012).

Tabla 7. Número de notas por candidato y noticiero

\begin{tabular}{|c|c|c|c|c|c|c|}
\hline \multirow{2}{*}{ Candidato } & \multicolumn{2}{|c|}{ "El Noticiero" } & \multicolumn{2}{|c|}{ "Hechos" } & \multirow{2}{*}{ Total notas } & \multirow{2}{*}{ Total \% } \\
\hline & Notas & $\%$ & Notas & $\%$ & & \\
\hline EPN & 38 & 34.5 & 22 & 44.0 & 60 & 37.5 \\
\hline AMLO & 38 & 34.5 & 15 & 30.0 & 53 & 33.1 \\
\hline $\mathrm{JVM}$ & 34 & 31.0 & 13 & 26.0 & 47 & 29.4 \\
\hline Total & 110 & 100.0 & 50 & 100.0 & 160 & 100.0 \\
\hline
\end{tabular}

Fuente: Elaboración propia con datos de EGAP (2012).

Estar expuestos a un mensaje publicitario activa nuestra desconfianza debido a la intención expresamente persuasiva del emisor. En cambio, el material noticioso es percibido, al menos en principio, como objetivo y sin fines expresos de persuasión comercial o política por parte del medio de comunicación que lo difunde (Juárez, 2012: 3).

Durante los ocho meses previos al inicio de las precampañas, se detectaron en los noticieros monitoreados 41 materiales de Peña Nieto que cumplen con las características de "infomerciales", es decir, poco más de cinco promocionales disfrazados por mes, con particular acento en abril, cuando se transmitieron ocho segmentos, junio con $10 \mathrm{y}$ agosto con nueve.

\section{Precampañas e intercampañas}

De facto, las precampañas empezaron desde septiembre, una vez que EPN concluyó su encargo en la gubernatura del Estado de México y cuando jvm y Santiago Creel renunciaron a sus responsabilidades legislativas para buscar la candidatura del PAN.
Oficialmente, el comienzo de las precampañas fue el 19 de diciembre de 2011. Sólo el partido blanquiazul tuvo contienda interna, en el estricto sentido del término, pues las otras dos fuerzas políticas eligieron precandidatos únicos, es decir, el espacio se utilizó para posicionar al virtual candidato entre el electorado en general y no, como marca la legislación, entre los militantes o sufragantes del proceso interno. En este periodo, la presencia en los medios de los futuros candidatos de los partidos distintos al PRI se eleva y disminuye la de éste, con lo que se alcanza un equilibrio casi perfecto respecto de la cobertura de los noticieros televisivos. Como puede verse en la tabla 7 , mientras que antes del inicio de las precampañas Peña Nieto acaparaba casi dos terceras partes del espacio en los noticieros, durante estos cuatro meses, que el IFE monitorea, su presencia se reduce a sólo la tercera parte.

En la sumatoria de la cantidad de segundos de los dos noticieros que se hace en la tabla 8 se aprecia que López Obrador recibe poco menos de la tercera parte, en particular por el incremento en la presencia de Vázquez Mota, que prácticamente estaba 
Tabla 8. Cantidad de segundos por candidato y noticiero

\begin{tabular}{lccccccc}
\hline Candidato & "El Noticiero" & $\%$ & "Hechos" & $\%$ & \multicolumn{2}{c}{ Total } & noticieros \\
\hline EPN & 2152 & 30.8 & 1280 & 39.9 & 3432 & 33.7 \\
\hline AMLO & 1892 & 27.1 & 846 & 26.4 & 2738 & 26.8 & 39.5 \\
\hline JVM & 2950 & 42.1 & 1080 & 33.7 & 4030 & 10200 & 100.0 \\
\hline Total & 6994 & 100.0 & 3206 & 100.0 & 100 \\
\hline
\end{tabular}

Fuente: Elaboración propia con datos de EGAP (2012).

Tabla 9. Número de notas por candidato y periódico

\begin{tabular}{lccccccc}
\hline \multirow{2}{*}{ Periódico } & \multicolumn{3}{c}{ EPN } & \multicolumn{3}{c}{ AMLO } & \multicolumn{2}{c}{ JVM } & Total \\
\cline { 2 - 7 } & Notas & $\%$ & Notas & $\%$ & Notas & $\%$ & \\
\hline El Universal & 32 & 50.8 & 18 & 28.6 & 13 & 20.6 & 63 \\
\hline La Jornada & 13 & 39.4 & 11 & 33.3 & 9 & 27.3 & 33 \\
\hline Reforma & 14 & 58.4 & 2 & 8.3 & 8 & 33.3 & 24 \\
\hline Total & 59 & 49.2 & 31 & 25.8 & 30 & 25.0 & 120 \\
\hline
\end{tabular}

Fuente: Elaboración propia con datos de EGAP (2012).

desaparecida de los medios y recibe 39\% del tiempo. En los medios impresos también crece la presencia de la precandidata panista, mínima hasta entonces. En los noticieros su presencia se multiplicó casi cuatro veces como consecuencia del espacio que le brindó "El Noticiero". En los diarios figuró tres veces más, de manera equilibrada en las tres publicaciones, si bien de forma un poco más pronunciada en Reforma y El Universal, en los que las menciones se multiplicaron cuatro y poco más de tres veces, respectivamente. Hay dos explicaciones posibles: ser el único partido que realizó elección interna y que en marzo todo parecía indicar que ella se posicionaría en el segundo lugar de la contienda y, eventualmente, podría ser la principal contendiente del priista.

\section{Las campañas electorales}

El periodo de las campañas electorales abarca abril, mayo y junio y presenta un incremento en la cobertura de los tres principales contendientes por la presidencia de la república. Durante estos 90 días y hasta el miércoles 27 de junio - cuando cerraron las campañas de conformidad con la legislación electoral- hubo 64 emisiones de los noticieros televisivos, y 66 si se incluyen los noticieros de jueves $\mathrm{y}$ viernes, en los que de cualquier manera se difundió información de los candidatos. En estas 66 emisiones se transmitieron en promedio diario 16 minutos y 54 segundos de información relacionada con los candidatos de las tres fuerzas políticas con mayor participación electoral: 10 minutos 16 segundos correspondientes a "El Noticiero" y 6 minutos 38 segundos, a "Hechos". En este tiempo se contemplan informaciones, opiniones de los especialistas y las secciones de parodia y humor, no únicamente los espacios informativos en los que aparezca el candidato -imagen y/o voz-.

Las televisoras fueron especialmente cuidadosas en dedicar casi el mismo espacio a cada uno de los candidatos, y a pesar de que hay diferencias en el tono, en particular en relación con el candidato del Movimiento Progresista, también trataron de no hacerlo ostensible, con la clara intención de cumplir, 
Tabla 9. Cantidad de segundos por candidato y noticiero

\begin{tabular}{|c|c|c|c|c|c|c|c|}
\hline \multirow{2}{*}{ Noticiero } & \multicolumn{2}{|c|}{$E P N$} & \multicolumn{2}{|c|}{$A M L O$} & \multicolumn{2}{|c|}{$J V M$} & \multirow{2}{*}{ Totala } \\
\hline & Segundos & $\%$ & Segundos & $\%$ & Segundos & $\%$ & \\
\hline $\begin{array}{l}\text { "El } \\
\text { Noticiero" }\end{array}$ & 14588 & 35.9 & 13570 & 33.4 & 12494 & 30.7 & 40652 \\
\hline "Hechos" & 9912 & 37.7 & 9363 & 35.6 & 7000 & 26.7 & 26275 \\
\hline Total & 24500 & & 22933 & & 19494 & & 66927 \\
\hline$\%$ & 36.6 & & 34.3 & & 29.1 & & 100 \\
\hline
\end{tabular}

Tabla 10. Cantidad de segundos por candidato y noticiero clasificado por tono

\begin{tabular}{|c|c|c|c|c|c|c|c|}
\hline \multirow{2}{*}{ Candidato } & \multirow{2}{*}{ Tono } & \multicolumn{2}{|c|}{ "El Noticiero" } & \multicolumn{2}{|c|}{ "Hechos" } & \multirow{2}{*}{$\begin{array}{c}\text { Total } \\
\text { segundos }\end{array}$} & \multirow{2}{*}{ Total \% } \\
\hline & & Segundos & $\%^{a}$ & Segundos & $\%$ & & \\
\hline EPN & \multirow{3}{*}{ Neutro } & 11213 & 76.87 & 7664 & 77.32 & 18877 & 77.05 \\
\hline AMLO & & 10237 & 75.44 & 6467 & 69.07 & 16704 & 72.84 \\
\hline JVM & & 10995 & 88.0 & 5372 & 76.74 & 16367 & 83.96 \\
\hline EPN & \multirow{3}{*}{ Negativo } & 2722 & 18.66 & 1738 & 17.53 & 4460 & 18.21 \\
\hline AMLO & & 3213 & 23.68 & 2896 & 30.93 & 6109 & 26.64 \\
\hline JVM & & 1000 & 8.0 & 1547 & 22.09 & 2547 & 13.07 \\
\hline EPN & \multirow{3}{*}{ Positivo } & 653 & 4.48 & 510 & 5.15 & 1163 & 4.74 \\
\hline AMLO & & 120 & 0.88 & 0 & 0.0 & 120 & 0.52 \\
\hline JVM & & 499 & 4.0 & 81 & 1.16 & 580 & 2.97 \\
\hline Total & & 40652 & & 26275 & & 66927 & \\
\hline
\end{tabular}

${ }^{a}$ Los porcentajes se calculan en función del tiempo total dedicado a cada uno de los candidatos. En el total es lo mismo el porcentaje de tiempo que cada candidato recibió en los dos noticieros.

Fuente: Elaboración propia con datos de EGAP (2012).

al menos en los espacios monitoreados por el IFE, con la normatividad vigente. Respecto del tiempo total dedicado a cada uno de los tres principales candidatos las diferencias son menores, como puede observarse en la tabla 9, aunque un poco más marcadas entre Peña Nieto y Vázquez Mota, que presentan una brecha de 83 minutos que, divididos entre los 66 días de transmisiones, se traducen en 1 minuto 15 segundos diarios, muy representativos en tiempo de televisión. Sin embargo, la mayor diferencia se encuentra en el tono de las informaciones, pues al colocar esta calificación el tratamiento distinto se torna más evidente, como se constata en la tabla 10. Vázquez Mota, que fue la que menos tiempo de cobertura total recibió, se vio favorecida porque fue a la que se le dedicó menos tiempo negativo. Peña Nieto fue quien más tiempo total y positivo tuvo. En cambio, López Obrador fue el que más tiempo negativo acaparó: casi dos y media veces más que la candidata del blanquiazul y casi $40 \%$ más que el tricolor. Al sumar todas estas variables el total de tiempo neutro y positivo de EPN alcanza 5 horas y 34 
Tabla 11. Número de notas por candidato y periódico

\begin{tabular}{|c|c|c|c|c|c|c|c|}
\hline \multirow{2}{*}{ Periódico } & \multicolumn{2}{|c|}{$E P N$} & \multicolumn{2}{|c|}{$A M L O$} & \multicolumn{2}{|c|}{$J V M$} & \multirow{2}{*}{ Total } \\
\hline & Notas & $\%$ & Notas & $\%$ & Notas & $\%$ & \\
\hline El Universal & 43 & 35.8 & 42 & 35.0 & 35 & 29.2 & 120 \\
\hline La Jornada & 29 & 40.8 & 29 & 40.8 & 13 & 18.4 & 71 \\
\hline Reforma & 21 & 58.3 & 6 & 16.7 & 9 & 25.0 & 36 \\
\hline Total & 93 & 41.0 & 77 & 33.9 & 57 & 25.1 & 227 \\
\hline
\end{tabular}

Fuente: Elaboración propia con datos de EGAP (2012).

minutos en los 66 días, el de AMLO, 4 horas y $40 \mathrm{mi}$ nutos, y el de JVM, 4 horas y 23 segundos. Es decir, durante la campaña electoral el candidato tricolor tuvo 54 minutos más de exposición neutra o positiva que el perredista y 1 hora 11 minutos más que la panista. La diferencia no es menor. También resulta significativo que los porcentajes del tiempo neutro, negativo y positivo que las dos televisoras difundieron sobre el candidato de la Coalición Compromiso por México son casi idénticos. Las diferencias se encuentran en el tono del tiempo dedicado a los otros dos candidatos: TVAzteca dedica más tiempo negativo a AMLO y a Jvm que Televisa.

Por falta de espacio no se analizan a detalle los movimientos conforme se acercan las elecciones, pero es conveniente señalar que durante abril se destinaron en los dos noticieros 5579 segundos a la información de los tres candidatos, apenas $8.3 \%$ del tiempo total; en mayo se incrementó a $26576,39.7 \%$, y en junio se elevó a $34772,52 \%$. Más de la mitad del tiempo de cobertura se concentra en el último mes de campaña. Otro aspecto interesante es que mientras en el primer mes la cobertura se distribuye prácticamente en partes iguales entre los tres candidatos, para el último mes la candidata del blanquiazul alcanzó únicamente $26.7 \%$ de la cobertura, es decir, perdió atención al relegarse al tercer lugar en la carrera por la presidencia. Conforme se acerca la elección la cobertura negativa en relación con López Obrador también crece, hasta alcanzar más de la tercera parte en junio. En el caso de Peña Nieto el pico de cobertura negativa fue en mayo y disminuyó en junio, a pesar de que en ese mes Alatorre entrevistó a los cuatro candidatos, y AMLO y JVM aprovecharon parte de ese espacio para descalificar a su oponente.

En los periódicos la situación es distinta, pues se rompe la uniformidad que existe entre las televisoras y los tres diarios manifiestan diversidad en sus coberturas. Además, también disminuye de manera notable el porcentaje de notas que se pueden clasificar en tono neutral y un porcentaje importante se ubica en el tono negativo. La tabla 11 muestra el número y el porcentaje de notas que cada candidato tuvo en las primeras páginas de cada uno de los diarios durante las 93 ediciones previas a la jornada electoral. El que mayores cambios presenta es $E l$ Universal, pues del espacio de primera plana que le otorgaba a los candidatos presidenciales pasa de brindarle las dos terceras partes a Peña Nieto durante los ocho meses previos al inicio de las precampañas a $51 \%$ durante las precampañas y a $35.8 \%$ durante las campañas electorales. Los espacios que libera los reparte con equilibrio relativo entre los otros dos candidatos. En cambio, La Jornada no modifica el porcentaje que le dedica al priista, pero sí los del perredista y la panista, aunque no en tránsito hacia un mayor equilibrio. Reforma también mantiene el porcentaje del priista y mueve los otros, pero tampoco logra un balance. 
Tabla 12. Número de notas totales por candidato y periódico

\begin{tabular}{lcccccccc}
\hline Candidato & $\begin{array}{c}E l \\
\text { Universal }\end{array}$ & $\%$ & $\begin{array}{c}\text { La } \\
\text { Jornada }\end{array}$ & $\%$ & Reforma & $\%$ & Total & $\%$ \\
\hline EPN & 835 & 37.3 & 766 & 42.2 & 1137 & 43.1 & 2738 & 40.9 \\
\hline AMLO & 758 & 33.9 & 596 & 32.8 & 781 & 29.6 & 2135 & 31.9 \\
\hline JVM & 643 & 28.8 & 453 & 25.0 & 721 & 27.3 & 1817 & 27.2 \\
\hline Total & 2236 & 100 & 1815 & 100 & 2639 & 100 & 6690 & 100 \\
\hline
\end{tabular}

Fuente: Elaboración propia con datos de EGAP (2012).

El Universal opera de manera muy similar a las televisoras, es decir, aprovecha los meses previos para posicionar al candidato tricolor y alinea paulatinamente los espacios de cobertura cuando empiezan oficialmente las precampañas e incluso más durante las campañas electorales. Analizar las publicaciones totales y posteriormente su tono permite identificar con claridad las diferencias entre los medios. La tabla 12 muestra el total de notas - no sólo de primera plana- que los tres periódicos dedicaron a la cobertura de los tres candidatos presidenciales. De nuevo, como en la televisión, el candidato que más espacio ocupó fue Peña Nieto, seguido por López Obrador y finalmente por Vázquez Mota. Sin embargo, como se observa en la tabla 13, en el caso de los medios impresos el tono de la cobertura es más variado $y$, aunque predomina el tono neutro, los porcentajes de las notas con tono negativo o positivo son altos y en algunos casos predominantes, como la cantidad de notas negativas de La Jornada sobre EPN, con poco más de $53 \%$ del total.

Peña Nieto acapara las publicaciones de tono negativo en los tres periódicos. No obstante, los porcentajes difieren mucho, pues van de $29.05 \%$ en $E l$ Universal a $40.02 \%$ en Reforma y a $53.13 \%$ en $\mathrm{La}$ Jornada. En cuanto al tono neutro, Vázquez Mota es quien más notas acumuló, salvo en el caso de $L a$ Jornada, en el que López Obrador ocupa el primer lugar. Este mismo candidato reunió el mayor porcentaje de notas positivas, excepto en el Reforma, donde lo desplaza la candidata panista. La Jornada exhibe de manera indudable su postura a favor de AMLO, pues $31.04 \%$ de las informaciones o artículos publicados sobre el candidato tienen un tono positivo, contra únicamente $2.61 \%$ a favor de Peña Nieto y $2.21 \%$ de Vázquez Mota. Cuando se observan los porcentajes de los elementos negativos se repiten los sesgos: $13.59 \%$ contra AMLO, $44.15 \%$ contra JVM y el ya citado $53.13 \%$ contra EPN. Así, el espacio neutro se reduce en el caso del priista a sólo $44.26 \%$, el del perredista a $55.37 \%$ y el de la panista a $55.64 \%$.

En número absoluto de notas con tono neutro o positivo, López Obrador se coloca en primer lugar, con 1704 , que representan casi $80 \%$ del total de publicaciones que lo mencionan; le sigue Peña Nieto, con 1634, casi $60 \%$, y en tercer sitio Vázquez Mota, con 1330, que son 73\%. En El Universal, en números absolutos, Peña Nieto tiene el mayor número de publicaciones con tono neutro o positivo, aunque porcentualmente ocupa el tercer lugar. En La Jornada y Reforma López Obrador tiene el primer escaño en números absolutos, pero en el segundo diario es superado porcentualmente por Vázquez Mota, que de esta manera ocupa el primer lugar en términos relativos en El Universal y Reforma. En los medios impresos, tanto por los artículos de opinión como por la labor de investigación que realizan, la cobertura es menos neutra que en las televisoras. Esto permite identificar las posiciones de cada periódico, que en el caso de La Jornada es favorable a López Obrador. 
Tabla 13. Número de notas por candidato y periódico, clasificado por tono

\begin{tabular}{|c|c|c|c|c|c|c|c|c|c|}
\hline \multirow{2}{*}{ Candidato } & \multirow{2}{*}{ Tono } & \multicolumn{2}{|c|}{ El Universal } & \multicolumn{2}{|c|}{ La Jornada } & \multicolumn{2}{|c|}{ Reforma } & \multirow{2}{*}{$\begin{array}{c}\text { Total } \\
\text { notas }\end{array}$} & \multirow{2}{*}{ Total \% } \\
\hline & & Notas & $\%$ & Notas & $\%$ & Notas & $\%$ & & \\
\hline EPN & & 549 & 65.79 & 339 & 44.26 & 643 & 56.55 & 1531 & 55.9 \\
\hline AMLO & Neutro & 526 & 69.39 & 330 & 55.37 & 570 & 72.98 & 1426 & 66.8 \\
\hline JVM & & 464 & 72.16 & 243 & 53.64 & 537 & 74.48 & 1244 & 68.5 \\
\hline EPN & & 242 & 29.05 & 407 & 53.13 & 455 & 40.02 & 1104 & 40.3 \\
\hline AMLO & Negativo & 176 & 23.22 & 81 & 13.59 & 174 & 22.28 & 431 & 20.2 \\
\hline JVM & & 139 & 21.62 & 200 & 44.15 & 148 & 20.53 & 487 & 26.8 \\
\hline EPN & & 44 & 5.36 & 20 & 2.61 & 39 & 3.43 & 103 & 3.8 \\
\hline AMLO & Positivo & 56 & 7.39 & 185 & 31.04 & 37 & 4.74 & 278 & 13.0 \\
\hline JVM & & 40 & 6.22 & 10 & 2.21 & 36 & 4.99 & 86 & 4.7 \\
\hline Total & & 2236 & & 1815 & & 2639 & & 6690 & \\
\hline
\end{tabular}

Fuente: Elaboración propia con datos de EGAP (2012).

Con menos claridad, también es perceptible el antipriismo del Reforma, más cercano al PAN, si bien al final, ante la pérdida de preferencia electoral de su abanderada, se acerca más al perredista. En el caso de El Universal, su priismo se observa particularmente en los meses previos al inicio del proceso electoral.

\section{Un breve análisis cualitativo}

Un breve análisis cualitativo del tratamiento de dos temas particularmente relevantes durante la campaña electoral ayuda a identificar las posiciones de las televisoras y los diarios: la visita de Peña Nieto a la Universidad Iberoamericana (Ibero) y el llamado "charolazo" de gente cercana a López Obrador. El caso de la visita del candidato priista a la Ibero trasciende en el proceso electoral, porque a partir de esos acontecimientos surgió el Movimiento \#YoSoy132, que aglutinó a estudiantes de universidades privadas y públicas para manifestarse contra este candidato y demandar cambios en la normatividad en materia de medios masivos de comunicación para acabar con la actual concentración. Antes de acudir a la casa de estudios, EPN había cancelado una participación y cuando finalmente se concretó, el 11 de mayo, se hicieron presentes los estudiantes que manifestaron su rechazo al candidato tricolor, lo cual dio pie a que el presidente nacional del PRI los catalogara como ajenos a la universidad y los calificara de provocadores. El denominado "charolazo" es interesante porque el candidato de la Coalición Movimiento Progresista descalificaba a sus oponentes por estar entregados a los grupos económica o mediáticamente poderosos y su congruencia fue seriamente cuestionada porque sus colaboradores solicitaron recursos a empresarios mexicanos para sostener su campaña. A pesar de que en la misma grabación de audio que se dio a conocer - aunque no en el primer momento- de la citada reunión se escuchaba que los organizadores de la cena deslindaban del evento a su abanderado, no era creíble que una acción de esa naturaleza se realizara sin su conocimiento. 
En el primer evento, ocurrido el 11 de mayo, "El Noticiero" dedicó el mismo día 5 minutos y 22 segundos, de los cuales durante 1 minuto 30 segundos se transmitió el mensaje de Peña Nieto respecto del caso Atenco y 2 minutos 22 segundos correspondieron a un mensaje de audio de Luis Videgaray, coordinador de la campaña del priista, en el que pondera la actitud del candidato ante las protestas de los estudiantes. Así, tres cuartas partes del tiempo transcurrió con mensajes favorables a Peña Nieto y menos de una cuarta parte muestra las protestas de los jóvenes. En general, la imagen que transmiten del candidato es la de alguien propositivo, tolerante y dispuesto al diálogo. En "Hechos" la noticia ocupó 1 minuto 20 segundos: un minuto para la transmisión del video y audio de Peña Nieto sobre el caso
Atenco y en el resto del tiempo no se mencionan los incidentes de la visita del candidato.

En los medios impresos la historia es distinta. El Universal dedica su primera plana a EPN desde el mismo 11 de mayo - es decir, antes de que Peña Nieto visitara la Ibero- $-y$ alerta sobre el recibimiento que los alumnos darían al candidato. El encabezado decía: 'Preparan alumnos de la Ibero 'bienvenida' a Peña" y en la nota se da a conocer que a través de las redes sociales se organizaban para hacerle preguntas incómodas y manifestaciones de protesta. Al día siguiente, de nuevo en primera plana, continúan con la información a partir del encabezado: "Peña ofrece respeto a las voces críticas", con lo que subrayan la actitud tolerante y respetuosa del candidato ante los actos que organizaron los universitarios. Reforma

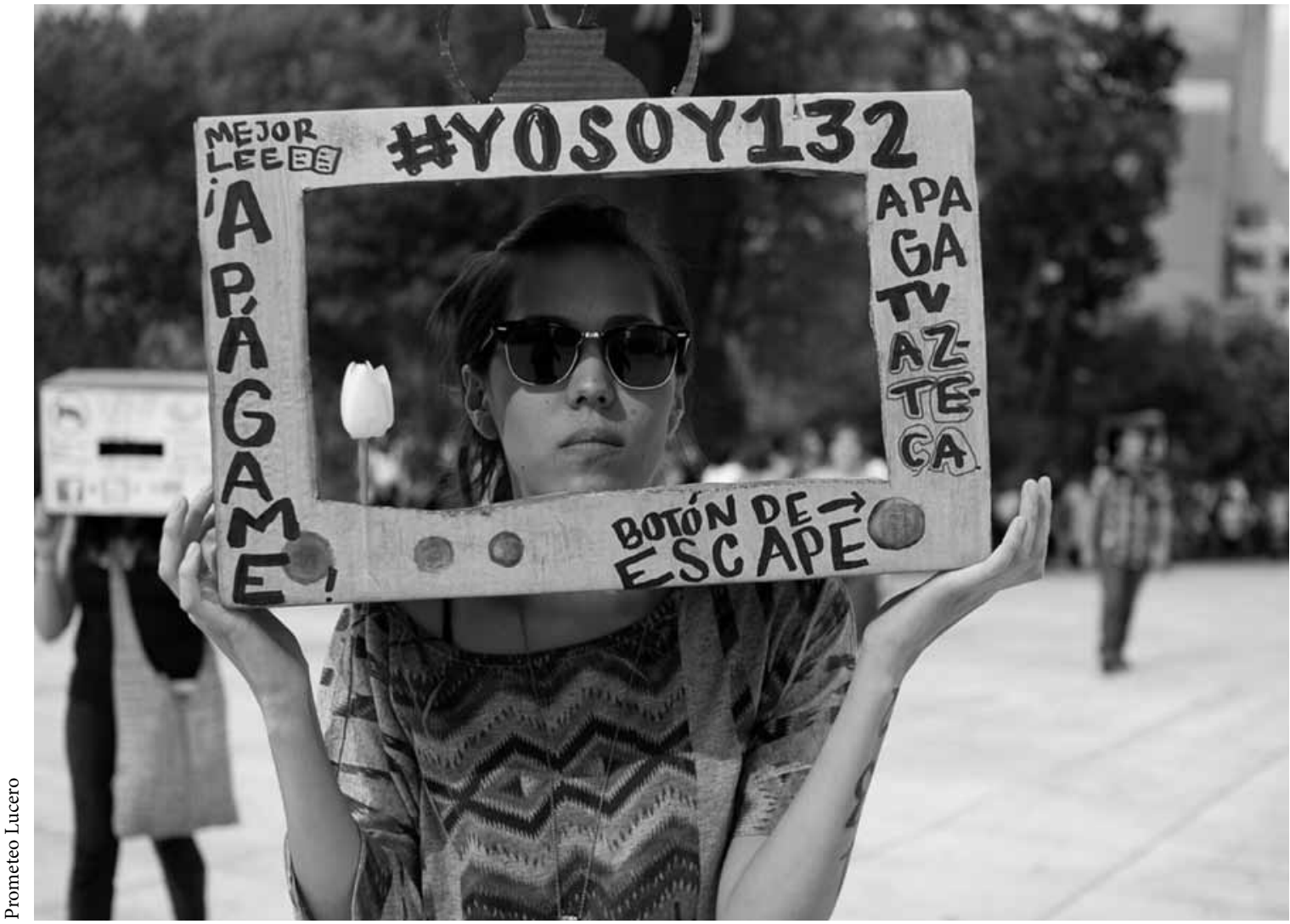

Performance de \#YoSoy132 en el metro de la ciudad de México, 13 de junio de 2012. 
titula la nota del 12 de mayo: "Sufre Peña en la Ibero" y destaca que la visita programada inicialmente en abril se pasó a mayo y que los seguidores de Peña Nieto llegaron antes de las 8 de la mañana, a pesar de que la conferencia estaba programada para las 10, para ocupar las primeras filas del auditorio, lo que irritó a los jóvenes universitarios que no alcanzaron un lugar. La nota narra los acontecimientos y las protestas contra el candidato del tricolor. Proyecta el enfrentamiento entre priistas y estudiantes y una imagen del candidato acorralado. $\mathrm{La}$ Jornada publica la información en primera plana con el encabezado: "La Ibero no te quiere', gritan a Peña Nieto", y ofrece una crónica de lo sucedido en la que relata las expresiones favorables y desfavorables al candidato tricolor. El saldo es claro: Televisa y El Universal proyectan la imagen de un candidato capaz de enfrentar las situaciones más incómodas con una actitud respetuosa y tolerante, TVAzteca ignora el acontecimiento, mientras Reforma y La Jornada resaltan las protestas.

En relación con el "charolazo", el 30 de mayo $E l$ Universal hace saber que seis días antes, el 24 de mayo, un grupo cercano al candidato Andrés Manuel López Obrador solicitó a un grupo de empresarios mexicanos donativos por seis millones de dólares para impulsar la campaña del perredista. Respalda la información con las transcripciones parciales de una grabación de audio realizada durante la cena celebrada en casa de Luis Creel. Esa misma noche, "El Noticiero" incluye la información entre sus titulares y posteriormente le dedica $13 \mathrm{mi}$ nutos al suceso. Primero reproduce durante cuatro minutos y medio la grabación en la que se escuchan las voces de los allegados a AMLO al solicitar el apoyo, después transmite durante un minuto las explicaciones del candidato, que se deslinda de las gestiones de sus allegados, mismas que interrumpe Joaquín López Dóriga para recordar que en el pasado López Obrador dijo no conocer a Luis Costa Bonino - asesor en imagen y comunicación- y transmite el registro auditivo en el que el candidato dice que no mentía, simplemente que no lo recordaba. Dedica el resto del tiempo a los posicionamientos de las fuerzas políticas sobre el asunto. Al día siguiente, "El Noticiero" destina otro minuto y 43 segundos a la conferencia matutina de AMLO, en la que habla de lo ocurrido y critica a Televisa y a $E l$ Universal por ocuparse del tema. Para cerrar la nota López Dóriga aclara: "Eso de que le dediqué casi todo el noticiero a la nota de la petición de seis millones de dólares, eso no es verdad, eh". La cobertura transmite la imagen de un López Obrador incongruente, mentiroso y trasgresor de la ley electoral.

"Hechos" no difunde la noticia el miércoles 30 de mayo, la retoma el jueves 31 con declaraciones del representante del PRI ante el IFE, Sebastián Lerdo de Tejada, quien manifiesta que interpondrán una queja ante las autoridades electorales, para que investiguen los hechos y el deslinde de AMLO. En total 2 minutos y 2 segundos. El Universal, medio que inició la noticia, le dedica espacios en primera plana y en interiores desde el primer día. El jueves 31 titula su nota de primera plana: "Polemizan por pase de charola", y básicamente reproduce opiniones adversas al hecho e incorpora las aclaraciones de López Obrador. Debe destacarse que la grabación con la que se revela la noticia se presenta inicialmente incompleta, sin la parte en la que los allegados a AMLO señalan que éste no los comisionó ni les autorizó para hacer la petición. Sobresale también que, contrario a las declaraciones de López Obrador, Luis Costa Bonino sí es asesor de su campaña, como afirmaba López Dóriga. En general, se transmite una imagen negativa de AMLO.

Reforma publica la información el 31 de mayo en interiores. Se orienta a la exigencia priista de investigar el "charolagate", pero incluye declaraciones de los personajes involucrados. El viernes 1 de julio publica la solicitud de pruebas del IFE para poder investigar. En general, minimiza el acontecimiento y da cabida principalmente a las solicitudes del PRI y a las declaraciones de la autoridad electoral. Por su parte, $L a$ Jornada reportó el hecho igualmente en interiores el 
Tabla 14. Medio de información y preferencias electorales

\begin{tabular}{|c|c|c|c|c|}
\hline $\begin{array}{c}\text { Medio de información/ } \\
\text { candidato }\end{array}$ & $J V M$ & $E P N$ & $A M L O$ & $G Q T$ \\
\hline Resultado IFE & 26.1 & 39.2 & 32.4 & 2.3 \\
\hline Total encuesta EGAP ${ }^{a}$ & 25.2 & 38.9 & 32.3 & 3.6 \\
\hline Únicamente $\mathrm{TV}^{\mathrm{b}}$ & 24.9 & 48.3 & 23.6 & 3.2 \\
\hline Únicamente internet $^{c}$ & 22.9 & 16.7 & 57.8 & 2.6 \\
\hline Periódicos $^{\mathrm{d}}$ & $\begin{array}{r}23.7 \\
(19.1-28.2)\end{array}$ & $\begin{array}{r}36.4 \\
(32.2-40.6)\end{array}$ & $\begin{array}{r}35.9 \\
(31.7-40.1)\end{array}$ & $\begin{array}{r}4.1 \\
(0-9.2)\end{array}$ \\
\hline Radio $^{e}$ & $\begin{array}{r}30.0 \\
(25.9-34.1)\end{array}$ & $\begin{array}{r}36.5 \\
(32.6-40.4)\end{array}$ & $\begin{array}{r}30.0 \\
(25.9-34.1)\end{array}$ & $\begin{array}{r}3.5 \\
(0-8.3)\end{array}$ \\
\hline \multicolumn{5}{|c|}{$\begin{array}{l}\text { a Se aplicaron } 2141 \text { entrevistas por teléfono celular a ciudadanos en condiciones de votar entre el } 25 \text { y el } 28 \text { de junio de } 2012 \text {. La muestra fue } \\
\text { estadísticamente seleccionada. La responsable del levantamiento fue la doctora Olivia Carrillo, del Departamento de Matemáticas del Instituto } \\
\text { Tecnológico de Estudios Superiores de Monterrey, Campus Monterrey. Las llamadas telefónicas se hicieron a través del call center del Sorteo Tec de } \\
\text { la misma institución. } \\
\text { b Se incluyen } 928 \text { entrevistados }-43.3 \% \text { del total-que dicen informarse de las campañas electorales únicamente a través de la televisión. } \\
\text { c Se incluyen } 270 \text { entrevistados }-12.6 \% \text { del total- que dicen informarse de las campañas electorales únicamente a través del internet. } \\
\text { d Se incluyen } 368 \text { entrevistados }-17.2 \% \text { del total- que dicen informarse de las campañas electorales a través de los periódicos, aunque no } \\
\text { necesariamente sin recurrir a algún otro medio, como la televisión o el internet. No fue posible limitar este universo a los que se informan } \\
\text { exclusivamente por este medio porque se reducía mucho el número de entrevistas y se elevaban los márgenes de error. } \\
\text { e Se incluyen } 424 \text { entrevistados - } 19.8 \% \text { del total- para los que dicen informarse de las campañas electorales a través de la radio, con las mismas } \\
\text { salvedades de la nota anterior. } \\
\text { Fuente: Elaboración propia con datos del proyecto "Medios y opinión pública" financiado por el Tecnológico de Monterrey y el Programa de las } \\
\text { Naciones Unidas para el Desarrollo. }\end{array}$} \\
\hline
\end{tabular}

31 de mayo. Destaca el deslinde de AmLo con un encabezado que señala: "No mando a nadie a pedir dinero para la campaña: López Obrador" y presenta la declaración completa. Expone asimismo las demandas del PRI y el PAN. El 1 de junio difunde las declaraciones de Yeidckol Polevnsky, responsable de administración y finanzas de la campaña de López Obrador, quien descalifica cualquier solicitud de dinero para la campaña. También minimiza el hecho y abre sus páginas a la defensa de López Obrador. Otra vez las posturas claras: Televisa y $E l$ Universal evidentemente contra López Obrador, TVAzteca se suma tímidamente, Reforma minimiza el acontecimiento y La Jornada defiende a AMLO. Los análisis estadísticos y de los casos descritos permiten constatar que los dos noticieros de televisión mantienen en lo general una misma línea de apoyo a
Peña Nieto, particularmente notable en la exposición previa y en el tono de la cobertura durante las campañas. En los medios impresos, El Universal apoya a Peña Nieto; La Jornada, a López Obrador, y el Reforma es principalmente antipriista.

\section{CONCLUSIONES}

Se constata que los medios masivos de comunicación mexicanos no son "políticamente neutrales" y, por ende, a pesar de las intenciones de los legisladores y las autoridades electorales, el pluralismo interno - es decir, que cada uno de los medios garantice la expresión de la diversidad mexicana, en este caso, de las ofertas políticas partidistas - no se logra en ninguno de los casos. Los dos noticieros televisivos 
estudiados se alinean a favor del candidato de la coalición conformada por PRI-PVEM. Esto es evidente en particular durante los meses previos al inicio de las precampañas. Análisis minuciosos de las coberturas, tanto a nivel cuantitativo como cualitativo, permiten detectar dicho sesgo durante las campañas electorales. Es decir, en los noticieros televisivos no se logra el pluralismo interno ni externo. En el caso de los periódicos editados en la capital de la república los sesgos son más evidentes, en especial en $L a$ Jornada, aunque también son constatables en los casos de El Universal y Reforma. Contrario a lo que sucede en la televisión, aquí sí se logra el pluralismo externo: El Universal con Peña Nieto, La Jornada con López Obrador y Reforma, antipriista pero con inclinación hacia el PAN, más perceptible en las etapas previas y menos durante las campañas electorales, principalmente porque la abanderada panista disminuyó sus preferencias electorales.

A partir de este análisis es muy difícil identificar el impacto de estos sesgos en el resultado electoral, sin embargo, sin inferir que hay una causalidad directa y su sentido, vale la pena comprobar las diferencias entre las preferencias electorales según el medio a través del cual se informa a la ciudadanía. Una encuesta levantada por la cátedra de investigación "Prácticas e instituciones de las democracias contemporáneas" de la EGAP Gobierno y Política Pública del Tecnológico de Monterrey muestra que las preferencias electorales difieren en relación con el medio de comunicación que la persona utilice para informarse de política. Más allá de las pruebas estadísticas que se hicieron para validar los resultados de la encuesta, la proximidad de sus resultados con los de la jornada electoral del 1 de julio de 2012 nos hace confiar en ella. Un aspecto en torno al cual hay que reflexionar.

Los que se informan únicamente por televisión, en la que hay un sesgo en la información a favor de Peña Nieto, muestran preferencias electorales marcadamente favorables para dicho candidato, como puede advertirse en la tabla 14. En cambio, los que lo hacen a través de periódicos, en los que hay pluralismo

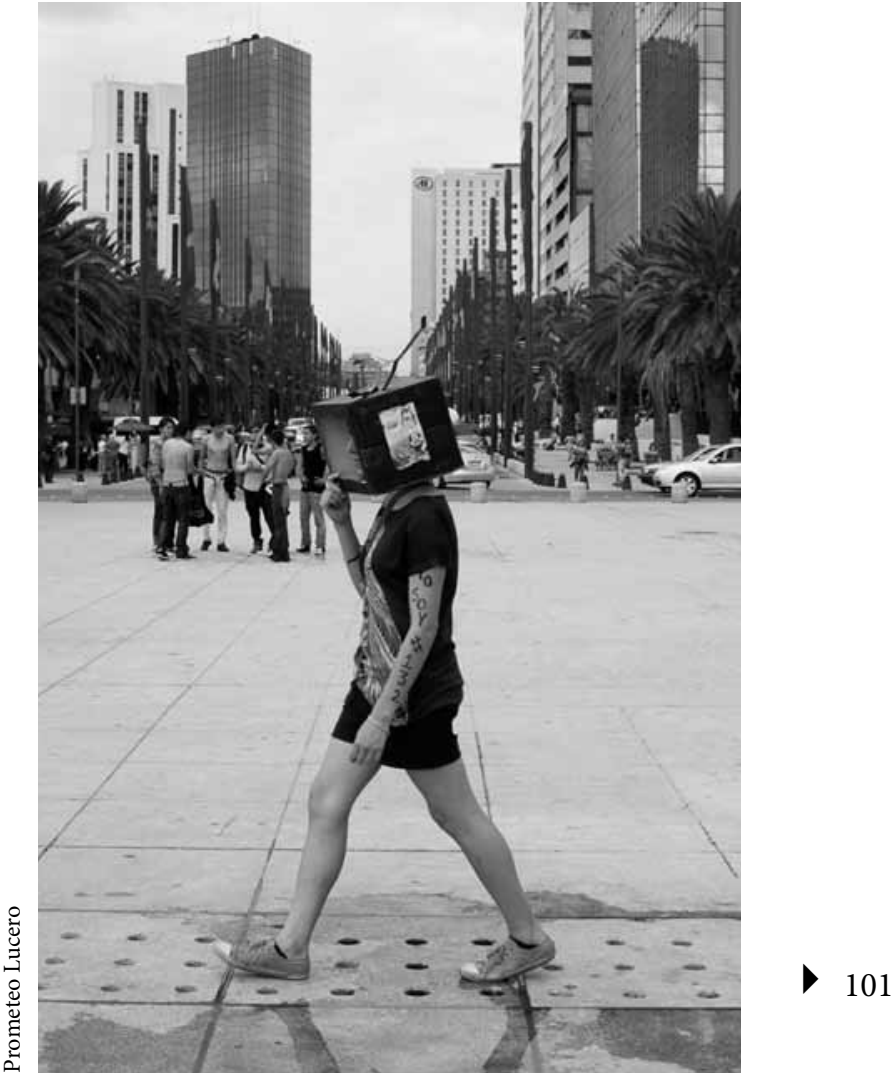

Performance de \#YoSoy132 en el metro de la ciudad de México, 13 de junio de 2012.

externo, dividen sus preferencias electorales entre los dos candidatos con mayor preferencia electoral, que son precisamente a los que favorecen los sesgos detectados en los medios. De hecho, de acuerdo con los márgenes de error, como puede apreciarse en la misma tabla 14 , con un nivel de confianza de $95 \%$ no sería posible predecir a un ganador, ya que los rangos estarían traslapados. Aunque no se hizo ninguna observación de los noticieros de radio, las preferencias electorales se dividen entre los tres candidatos con mayores preferencias electorales. En este caso se traslapan los rangos de los tres. Seguramente los perfiles sociodemográficos de los televidentes y de los lectores de periódicos son muy diferentes, pero también es de esperarse que sean más cercanos entre los televidentes y los radioescuchas. Del análisis 
realizado es posible concluir que las televisoras sí propician la desigualdad política, mientras que el pluralismo externo reinante en los medios impresos permite mayor igualdad. De la correlación entre medio de información y preferencias electorales no es posible concluir que el impacto de los medios incide definitoriamente en el resultado electoral, pero existen suficientes evidencias para presumirlo.

\section{BIBLIOGRAFÍA}

Beetham, David, 2004, "Fredom as the Foundation", en Journal of Democracy, vol. 15, núm. 4, The Quality of Democracy, pp. 61-75.

Cámara de Diputados del H. Congreso de la Unión, 2008, Código Federal de Instituciones y Procedimientos Electorales, Cámara de Diputados, en línea: <http://www. diputados.gob.mx/LeyesBiblio/pdf/COFIPE.pdf $>$.

Cantú, Jesús, 2012, "En pos de la profesionalización y democratización de los medios de comunicación”, en José Luis Calva (coord.), La agenda de la democracia en
Hallin, Daniel C. y Paolo Mancini, 2004, Comparing Media Systems. Three Models of Media and Politics, Cambridge University Press, Cambridge.

Huerta-Wong, Juan Enrique y Rogelio Gómez García, 2013, "Concentración y diversidad de los medios de comunicación y las telecomunicaciones", en Comunicación y Sociedad, núm. 19, enero-junio, México, pp. 113-152.

Juárez, Julio, 2012, "Análisis de material audiovisual a solicitud del IFE”, en Julio Juárez (coord.), Análisis de contenido y estructura de la publicidad política televisiva en el proceso electoral federal 2012, Centro de Investigaciones Interdisciplinarias en Ciencias y HumanidadesUniversidad Nacional Autónoma de México, México.

Pappathanassopoulos Stylianos, 2001, "Media Commercialization and Journalism in Greece", en European Journal of Communication, vol. 16, núm. 4, pp. 505-521.

Pérez Guajardo, Fernando, 2010, "Encuadre e ideología en la prensa mexicana”, tesina de la maestría en análisis político y medios de información, Escuela de Graduados en Administración Pública, Gobierno y Política Pública, Tecnológico de Monterrey, Monterrey.

Powell, Jr., G. Bingham, 2004, "The Chain of Responsiveness", en Journal of Democracy, vol. 15, núm. 4, The Quality of Democracy, pp. 91-105.

Rueschemeyer, Dietrich, 2004, "Addressing Inequality", en Journal of Democracy, vol. 15, núm. 4, The Quality of Democracy, pp. 76-90.

Schedler, Andreas, 2004, ¿Qué es la rendición de cuentas?, Instituto Federal de Acceso a la Información Pública, México.

Secretaría de Gobernación (Segob), 2012, "Encuesta Nacional de Cultura Política y Prácticas Ciudadanas", Secretaría de Gobernación, en línea: <http://www.encup. gob.mx/es/Encup/Quinta_ENCUP_2012>.

Trejo Delarbre, Raúl, 2011, "Quiénes controlan la televisión mexicana y dónde”, en Zócalo, año 12, núm. 137.

Zaharopoulos, Thimios y Manny E. Paraschos, 1993, Mass Media in Greece: Power, Politics and Privatization, Prager, Westport. 